\title{
The dynamics of electron beam scattering on metal membranes: nanopore formation in metal membranes using transmission electron microscopy
}

\author{
Hyun-Mi Kim ${ }^{1 *}$, Kyeong-Beom Park ${ }^{2}$, Hyung-Jun Kim² ${ }^{2}$,Hongsik Chae ${ }^{2}$, Jae-Seok Yu², Kidan Lee² \\ and Ki-Bum Kim ${ }^{1,2^{*}}$
}

\begin{abstract}
The dynamics of nanopore formation in metal membranes using the highly focused and high energy electron beams (e-beams) of transmission electron microscopy instruments was investigated. Various metals such as $\mathrm{Al}, \mathrm{Ti}, \mathrm{Cr}, \mathrm{Cu}$, and Au were selected to investigate the effect of the atomic mass of the metal on nanopore drilling, namely, elastic versus inelastic scattering. We demonstrated that the effect of elastic scattering (pore formation by sputtering) decreased as the atomic mass of the metal increased. Furthermore, experimental cross-sections obtained from normalized drilled volume vs. electron dose curves (characteristic contrast curves) matched well the calculated atomic displacement cross-sections determined from elastic scattering data. The sputtering energies of $\mathrm{Ti}, \mathrm{Cr}$, and $\mathrm{Cu}$ were determined to be approximately 10,9 , and $7 \mathrm{eV}$, respectively, which were in good agreement with the reported range of sputtering energy values.
\end{abstract}

Keywords: Nanopore perforation, Focused e-beam, Scattering cross-section

\section{Introduction}

Experimentally validating the idea of reading the sequence of nucleic acids of a single strand DNA by detecting the associated ionic current drop while the DNA is electrically driven through a nanopore is conditioned by the successful forming of nanometer scale pores in thin membranes. The work of Dekker et al. [1] who first reported the successful formation of nanopores in $\mathrm{SiN}_{\mathrm{x}}$ membranes using highly focused electron beams (e-beams) during transmission electron microscopy (TEM) studies, led to nanopores becoming one of the mainstream technologies for detecting small biomolecules in aqueous solutions. Prior to their study, there have been several reports about direct nanoscale sculpturing using the focused e-beams in TEM instruments

\footnotetext{
*Correspondence: hyunmi@snu.ac.kr; kibum@snu.ac.kr

${ }^{1}$ Research Institute of Advanced Materials (RIAM), Seoul National University, Seoul, South Korea

Full list of author information is available at the end of the article
}

[2]. In particular, material changes, typically referred to as "damage" caused by the high energy e-beams during TEM analysis have been a concern researchers have tried to understand and resolve for a long time [3, 4]. Efforts have been made to explain the damage employing the concept of energy transfer from the incident high energy particle (electron) to the rest of the atom. The perforating (sputtering) phenomena caused by the focused e-beam was also explained as a type of "damage" to the very thin material [5].

There are two different types of energy transfer processes the e-beam in TEM can be involved in: radiolysis due to the inelastic scattering of the electron-electron interactions resulting in specimen heating, ionization, and X-rays or Auger electrons generation, and knock-on damage due to the elastic scattering of the electron-atom interactions resulting in atomic displacement creating point defects within the materials or sputtered atoms at the surface of the specimens. Generally, it is known that the degree 
of energy transfer by radiolysis is reduced at higher e-beam energies while that of the knock-on damage is increased [3]. In our previous report [5], we summarized the theoretical prediction of each process (ionization, heating, and direct atomic displacement) on the energy transfer from high energy electrons to target materials based on the scattering cross-section, i.e., scattering probability, direct atomic displacement cross-section $\left(\sigma_{\mathrm{d}}\right)$ due to elastic scattering considering the relativistic kinematics of binary collisions (the Mott formula), and inelastic scattering cross-section $\left(\sigma_{\text {in }}\right)$ using the continuous slow down approximation (the Bethe formula). Here, $\sigma_{\mathrm{d}}$ is a function of the incident e-beam energy $(E)$, atomic mass $(M)$ of the target membrane and displacement energy $\left(E_{d}\right)$, which is the kinetic energy required to displace an atom from its original lattice position to an unstable one. Moreover, $\sigma_{\text {in }}$ is a function of $\mathrm{E}, \mathrm{M}$, and the electron excitation potential (I). From calculating $\sigma_{\mathrm{d}}$ as a function of $\mathrm{E}$, it was concluded that $\sigma_{\mathrm{d}}$ started to increase at the critical e-beam energy and continued to increase with increasing the electron beam energy, while $\sigma_{\text {in }}$ decreased with the increase in electron beam energy. We theoretically calculated $\sigma_{\mathrm{d}}$ and $\sigma_{\text {in }}$ for $\mathrm{SiN}_{\mathrm{x}}$ membranes and experimentally demonstrated that nanopore drilling in $\mathrm{SiN}_{x}$ membranes by the incident electron beam energy was the result of direct atomic displacement. The direct atomic displacement energy of $\operatorname{SiN}_{\mathrm{x}}(17 \mathrm{eV})$ could be determined from the evolution of nanopores as function of the energy and dose of the e-beam, and was well matched with the sputtering energy.

Solid-state nanopores using $\mathrm{SiN}_{\mathrm{x}}$ membranes are extensively adopted because of their simple fabrication process on $\mathrm{Si}$ substrates and easy perforation using TEM. However, the interest for metal embedded membranes for various applications such as zero mode wave guide structures for simultaneous electrical and optical measurements [6] and the fabrication of ion transistor structures [7-10] has been increasing. For these metal-containing structures, e-beam lithography and dry etching were commonly used to generate nanopores. However, these processes have limitations in forming nanopores with diameters smaller than $10 \mathrm{~nm}$. Therefore, studies on the formation of nanopores in metal membranes using focused e-beams have been conducted. In this article, we analyzed the direct atomic displacement cross-section in detail, calculated $\sigma_{\mathrm{d}}$ as a function of the e-beam energy for various metals, then evaluated nanopore drilling as a function of atomic mass and displacement energy for selected metals, and finally performed nanopore perforation in various metal membranes $(\mathrm{Ti}, \mathrm{Cr}$, and $\mathrm{Cu})$ using $200 \mathrm{kV}$ TEM.

\subsection{Theoretical calculation of $\sigma_{d}$}

The equation for calculating $\sigma_{\mathrm{d}}$ is given by the MckinleyFeshbach approximation [11] to the Mott and Massey expression [12] for high energy electrons as shown below [13]:

$$
\begin{aligned}
& \sigma_{\mathrm{d}}=4 \pi a_{0}^{2} E_{R}^{2} Z^{2}\left(\frac{1-\beta^{2}}{m^{2} c^{4} \beta^{4}}\right) \\
& {\left[\frac{E_{\max }}{E_{d}}+2 \pi \alpha \beta \sqrt{\frac{E_{\max }}{E_{d}}}-\left(\beta^{2}+\pi \alpha \beta\right) \ln \left(\frac{E_{\max }}{E_{d}}\right)-(1+2 \pi \alpha \beta)\right]}
\end{aligned}
$$

where $\mathrm{a}_{0}$ is the Bohr radius $\left(5.29 \times 10^{-11} \mathrm{~m}\right), \mathrm{E}_{\mathrm{R}}$ is the Rydberg energy for hydrogen $\left(\mathrm{E}_{\mathrm{R}}=\frac{m_{0} e^{4}}{2 \hbar^{2}}=13.606 \mathrm{eV}\right)$, $\alpha=\frac{\mathrm{Ze}^{2}}{\hbar c}=\mathrm{Z} / 137, \beta$ is a relativistic correction factor $\left(\beta=\mathrm{v} / \mathrm{c}=\sqrt{1-\left(1+E /\left(m c^{2}\right)\right)^{-2}}\right)$, and $\mathrm{Z}$ is atomic number of the target atom. In addition, $E_{\max }$ is the maximum transferred energy from the incident electron to the atom at rest $\left(E_{\max }=2 E\left(E+2 m c^{2}\right) / M c^{2}\right)$, where $\mathrm{m}$ is the mass of an electron, and $\mathrm{M}$ is the mass of the target atom. Furthermore, $E_{d}$ is the atomic displacement energy required to move an atom from its original position while generating a defect.

Therefore, $\sigma_{d}$ is a function of $E_{d}, M$, and $E$. To calculate $\sigma_{d}$ of metals, $E_{d}$ should be determined first. The value of $E_{d}$ is related to the bonding energy because inter-atomic bonds should be broken to dislocate an atom from its original lattice point. Sublimation energy $\left(E_{\text {sub }}\right)$ (i.e., the cohesive energy or bond dissociation energy [14]) is the energy required to convert a substance from solid to gas, and can be calculated from thermodynamic data. Therefore, this value is strongly correlated with the melting point. The reported $E_{d}$ and calculated $E_{\text {sub }}$ of various metallic elements are shown in Table 1 [15]. For metallic elements, $E_{d}$ in the bulk is reported to be approximately $\mathrm{E}_{\text {sub }} \times 4 \sim 5$ [16]. The sputtering energy $\left(\mathrm{E}_{\mathrm{s}}\right)$, which represents $E_{d}$ of the atoms at the surface of a sample, is smaller than $E_{d}$ in the bulk because atoms at the surface are less tightly bond than those in the bulk, and therefore, $\mathrm{E}_{\mathrm{s}} \sim 1 / 2 \mathrm{E}_{\mathrm{d}}$, usually $[17,18]$. Table 1 shows the estimated range of $\mathrm{E}_{\mathrm{s}}\left(1.5 \mathrm{E}_{\mathrm{sub}}<\mathrm{E}_{\mathrm{s}}<2.5 \mathrm{E}_{\text {sub }}\right)$.

We calculated $\sigma_{d}$ of metals using the middle values of the estimated energy ranges of $E_{s}$ as $E_{d}$. From the calculated $\sigma_{d}$ values, metals can be classified into three categories: (1) lightweight metals ( $\mathrm{Al})$ or low $\mathrm{E}_{\text {sub }}$ metals $(\mathrm{Zn}$ and $\mathrm{Cd})$, (2) heavy metals with high $\mathrm{E}_{\text {sub }}(\mathrm{Ag}, \mathrm{Au}$, and $\mathrm{Pt}$ ), and (3) transition metals ( $\mathrm{Ti}, \mathrm{Cr}, \mathrm{Cu}, \mathrm{Co}$, etc.). Figure 1 a shows the calculated $\sigma_{\mathrm{d}}$ of $\mathrm{Al}, \mathrm{Ti}, \mathrm{Cr}, \mathrm{Cu}$, and $\mathrm{Au}$ as a function of $\mathrm{E}$. $\mathrm{Al}$, which is a light metal (27 $\mathrm{amu})$ can be sputtered using e-beams with low energy, $\mathrm{E}<85 \mathrm{kV}$, while $\mathrm{Au}$, a heavier metal (79 amu) can be sputtered using e-beams with high energy, E $>450 \mathrm{kV}$. As can be seen in Fig. $1 \mathrm{~b}$, at $200 \mathrm{kV}, \sigma_{\mathrm{d}}$ starts decreasing with the increase in atomic mass. Generally, $\sigma_{d}$ decreases with the increase 
Table 1 Calculations and literature survey of $E_{d}, E_{\text {sub }}$, and $E_{s}$ for various metals

\begin{tabular}{|c|c|c|c|c|c|c|c|}
\hline Metal & Atomic number & Atomic weight & $E_{d}$ & $E_{\text {sub }}$ & $E_{s}$ & M.P. $\left({ }^{\circ} \mathrm{C}\right)$ & Structure \\
\hline Al & 13 & 26.98 & 16 & 3.4 & $5.1-8.5$ & 660 & $\mathrm{FCC}^{\mathrm{a}}$ \\
\hline $\mathrm{Ti}$ & 22 & 47.87 & 15 & 4.9 & $7.4-12.3$ & 1660 & $\mathrm{HCP} \mathrm{P}^{\mathrm{b}}$ \\
\hline V & 23 & 50.94 & 29 & 5.3 & $8.0-13.3$ & 1890 & $\mathrm{BCC}^{\mathrm{C}}$ \\
\hline $\mathrm{Cr}$ & 24 & 52 & 22 & 4.1 & $6.2-10.3$ & 1857 & $\mathrm{BCC}$ \\
\hline $\mathrm{Fe}$ & 26 & 55.85 & 16 & 4.3 & $6.5-10.8$ & 1535 & $\mathrm{BCC}$ \\
\hline $\mathrm{Ni}$ & 28 & 58.69 & 22 & 4.5 & $6.8-11.3$ & 1453 & FCC \\
\hline Co & 27 & 58.93 & 23 & 4.4 & $6.6-11.0$ & 1495 & $\mathrm{HCP}$ \\
\hline $\mathrm{Cu}$ & 29 & 63.55 & 18 & 3.5 & $5.3-8.8$ & 1083 & FCC \\
\hline Zn & 30 & 65.39 & 16 & 1.4 & $2.1-3.5$ & 420 & $\mathrm{HCP}$ \\
\hline $\mathrm{Nb}$ & 41 & 92.91 & 24 & 7.5 & $11.3-18.8$ & 2468 & $\mathrm{BCC}$ \\
\hline Mo & 42 & 95.94 & 27 & 6.8 & $10.2-17.0$ & 2617 & $\mathrm{BCC}$ \\
\hline $\mathrm{Ag}$ & 47 & 107.87 & 28 & 2.9 & $4.4-7.3$ & 962 & FCC \\
\hline $\mathrm{Cd}$ & 48 & 112.41 & 20 & 1.2 & $1.8-3.0$ & 321 & $\mathrm{HCP}$ \\
\hline $\mathrm{Ta}$ & 73 & 180.95 & 33 & 8.1 & $12.2-20.3$ & 2996 & $\mathrm{BCC}$ \\
\hline Pt & 78 & 195.08 & 33 & 5.9 & $8.9-14.8$ & 1772 & FCC \\
\hline $\mathrm{Au}$ & 79 & 196.97 & 36 & 3.8 & $5.7-9.5$ & 1064 & FCC \\
\hline
\end{tabular}

a FCC face centered cubic

${ }^{b}$ HCP hexagonal close packed

c BCC body centered cubic
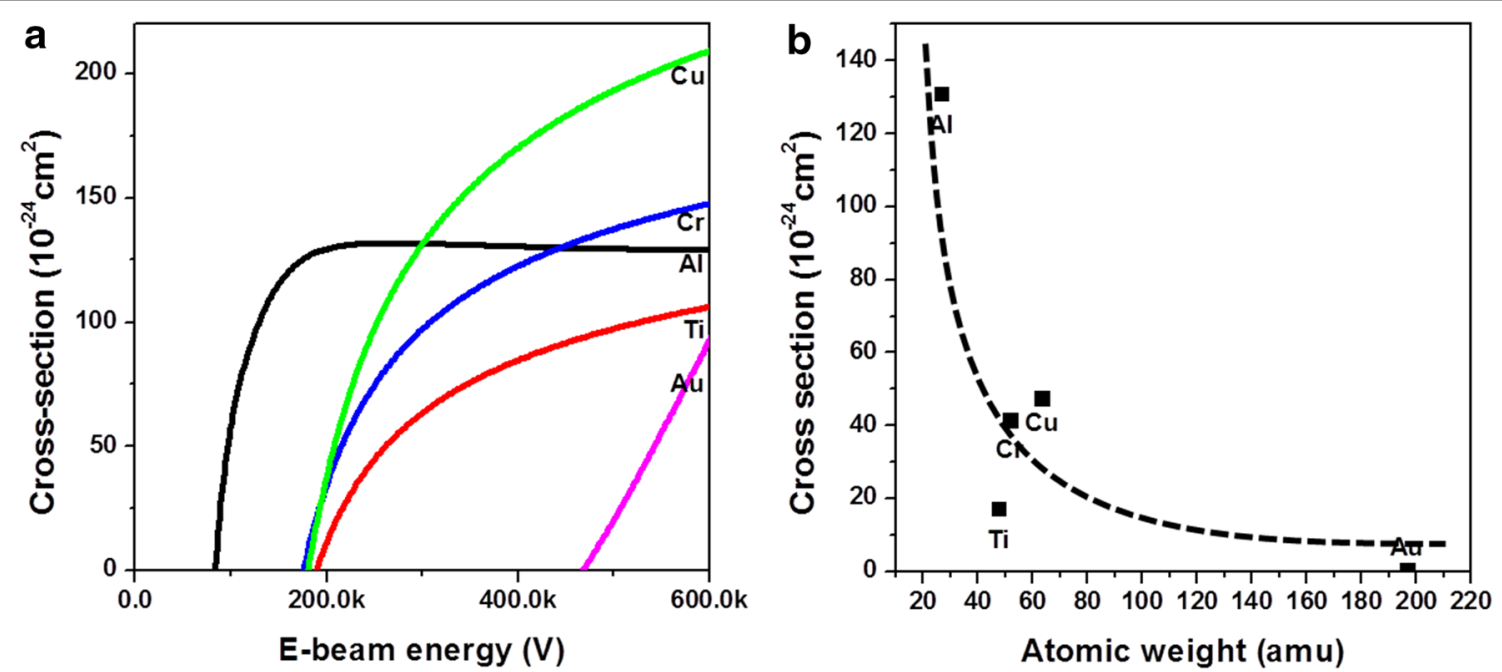

Fig. 1 a Calculated $\sigma_{d}$ as a function of $E$ and $\mathbf{b} \sigma_{d}$ as a function of atomic weight for $E=200 \mathrm{kV}$ for $\mathrm{Al}, \mathrm{Ti}, \mathrm{Cr}$, $\mathrm{Cu}$, and $\mathrm{Au}$

in atomic mass [19]. The critical dependence of $\sigma_{d}$ on the atomic mass of the target could explain the experimental results from previous reports, selective dissipation of light element such as oxygen and nitrogen in oxide and nitride $[2,20,21]$ and decrease in milling rate with increasing the atomic mass of the metal [19]. While $\mathrm{M}_{\mathrm{Ti}}$ $(22 \mathrm{amu})<\mathrm{M}_{\mathrm{Cr}}(24 \mathrm{amu})<\mathrm{M}_{\mathrm{Cu}}(29 \mathrm{amu})$, the corresponding $\mathrm{E}_{\text {sub }}$ values for these metals showed the inverse trend: $\mathrm{E}_{\text {sub }}(\mathrm{Ti}, 4.9 \mathrm{eV})>\mathrm{E}_{\text {sub }}(\mathrm{Cr}, 4.1 \mathrm{eV})>\mathrm{E}_{\text {sub }}(\mathrm{Cu}, 3.5 \mathrm{eV})$. As can be seen in Fig. 1 b, the calculated $\sigma_{d}$ values of $\mathrm{Ti}, \mathrm{Cr}$, and $\mathrm{Cu}$ at $200 \mathrm{kV}$ follow the same trend as $\mathrm{E}_{\text {sub. }}$.

\section{Experimental}

We evaporated $30 \mathrm{~nm}$ thick $\mathrm{Ti}, \mathrm{Cr}, \mathrm{Cu}$, and $\mathrm{Au}$ films on ultra-thin carbon film in $\mathrm{Cu}$ grids. For drilling and observing the nanopores, the samples were loaded in a TEM instrument with $200 \mathrm{kV}$ field emission guns (JEM2010F). The nanopores were drilled using the focused $200 \mathrm{kV}$ e-beam of the TEM instrument by varying the 
size of the aperture of the condenser lens $(\mathrm{CL})$. The aperture sizes of the CL used for our study were 150, 100, and $70 \mu \mathrm{m}$ and the total e-beam current values 7,3 , and $1.6 \mathrm{nA}$. The total e-beam current was measured using the viewing screen of a Keithley 6430 source meter [22]. Therefore, we were able to precisely calculate the electron flux $\left(\mathrm{e} / \mathrm{nm}^{2} \mathrm{~s}\right)$ by dividing the electron current $(\mathrm{C} / \mathrm{s})$ by the exposure area $\left(\mathrm{nm}^{2}\right)$. The exposure area was determined from the size and magnification of the e-beam on the viewing screen.

\section{Results and discussion}

Nanopores were drilled in various $30 \mathrm{~nm}$ thick metal membranes ( $\mathrm{Ti}, \mathrm{Cr}, \mathrm{Cu}$, and $\mathrm{Au}$ ) using a $200 \mathrm{kV}$ focused e-beam and different probe sizes by changing the aperture of the CL. Figure $2 \mathrm{a}-\mathrm{c}$ shows the TEM images of the evolution of nanopores in the $\mathrm{Ti}, \mathrm{Cr}$, and $\mathrm{Cu}$ membranes, respectively, as the e-beam exposure time increased from 20 to $90 \mathrm{~s}$ at an e-beam current of $7 \mathrm{nA}$. The $30 \mathrm{~nm}$ thick $\mathrm{Au}$ membrane could not be drilled using the $200 \mathrm{kV}$ e-beam; this $E$ value coincided with a zero $\sigma_{d}$ calculated value for Au. After the initial $20 \mathrm{~s}$ of e-beam exposure, the perforation occurred in a stable manner, and the minimum diameters of the nanopores were similar and approximately $2 \mathrm{~nm}$ each. The diameters of the nanopores gradually increased as the e-beam exposure time increased. The increase in e-beam exposure time brought changes in the diameter of the nanopores. After $90 \mathrm{~s}$ of exposure, the diameters of the nanopores for the $\mathrm{Ti}, \mathrm{Cr}$, and $\mathrm{Cu}$ membranes were $4.5,5$, and $6 \mathrm{~nm}$, respectively.

Figure $3 \mathrm{a}$ shows the resulting pore diameters as a function of the e-beam exposure time for various metal membranes for different e-beam current values. The square, circle, and triangle correspond to the $\mathrm{Ti}, \mathrm{Cr}$, and $\mathrm{Cu}$ membranes, and the solid and open dots correspond to the 7 and $3 \mathrm{nA}$ e-beam currents, respectively. For all experiments, the diameters increased with increasing the exposure time and eventually peaked. The largest diameters were 3 and $6 \mathrm{~nm}$ at 3 and $7 \mathrm{nA}$, respectively, which corresponded to the increase in the e-beam probe size by $\sim 2$ and $\sim 3 \mathrm{~nm}$, respectively. Reaching the peak pore diameter is a major advantage of nanopore perforation using focused e-beams. The increase in nanopore diameters was similar for the $\mathrm{Ti}$ and $\mathrm{Cr}$ membranes. The increase in pore diameter for the $\mathrm{Cu}$ membrane occurred faster than for other membranes, although $\mathrm{Cu}$ was the

\section{a Ti membrane with $30 \mathrm{~nm}$ thickness}
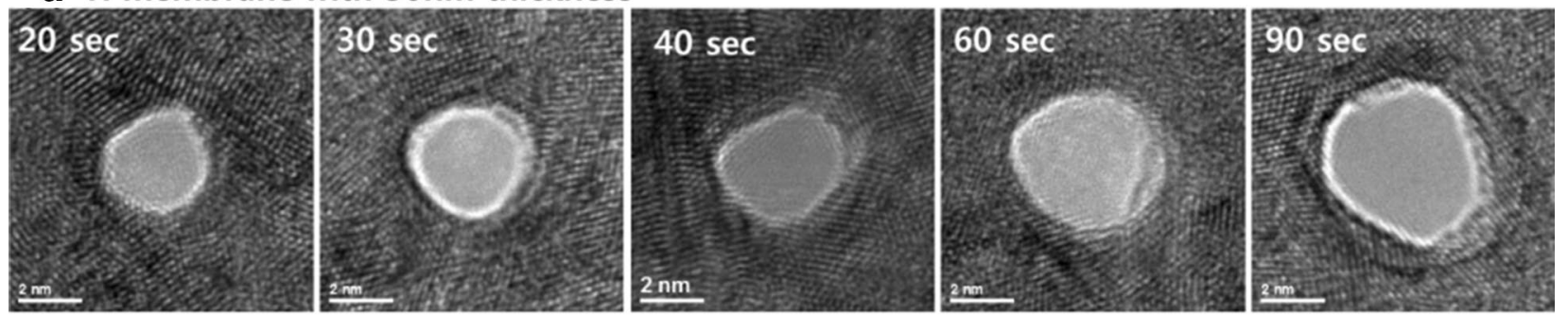

\section{b Cr membrane with $30 \mathrm{~nm}$ thickness}
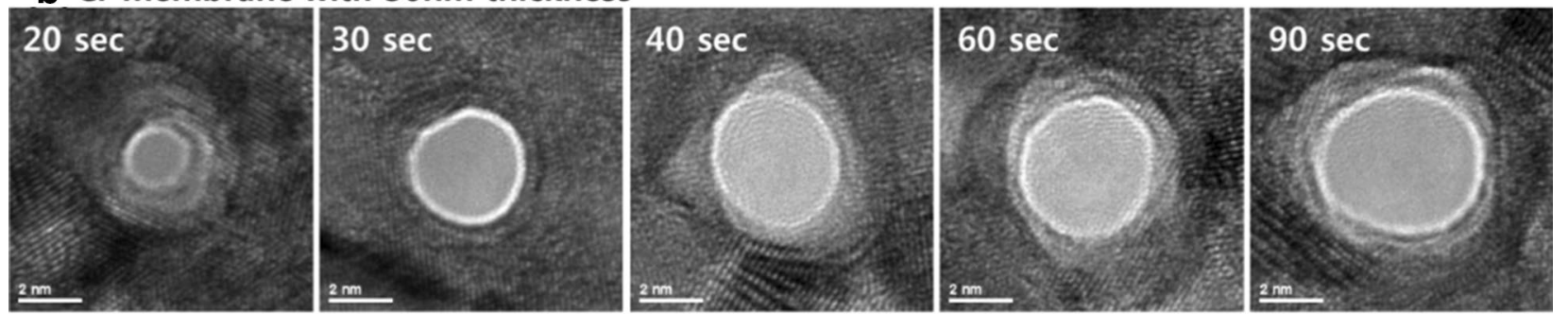

\section{c Cu membrane with $30 \mathrm{~nm}$ thickness}
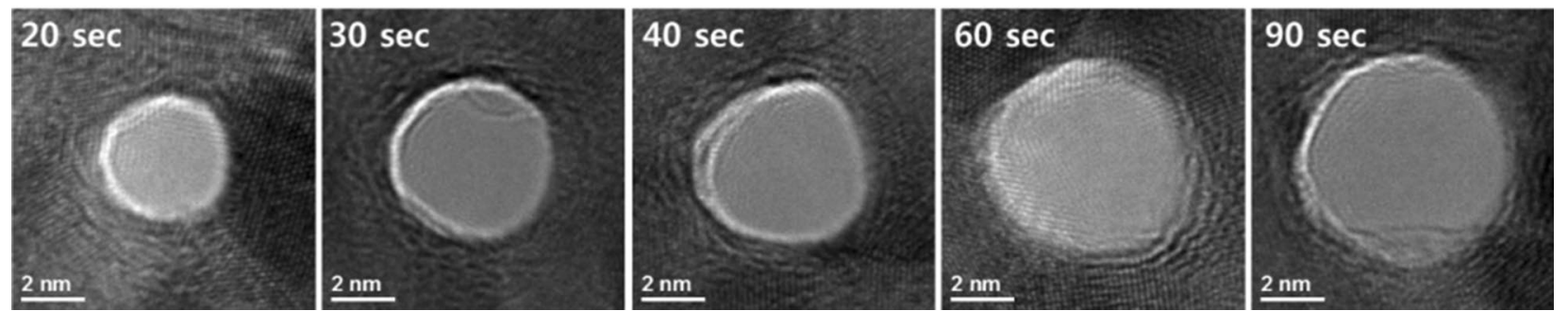

Fig. 2 Nanopore evolution for $30 \mathrm{~nm}$ thick $\mathbf{a} \mathrm{Ti}, \mathbf{b} \mathrm{Cr}$, and c Cu membranes with e-beam exposure time, at $200 \mathrm{kV}$ and $7 \mathrm{nA}$ 

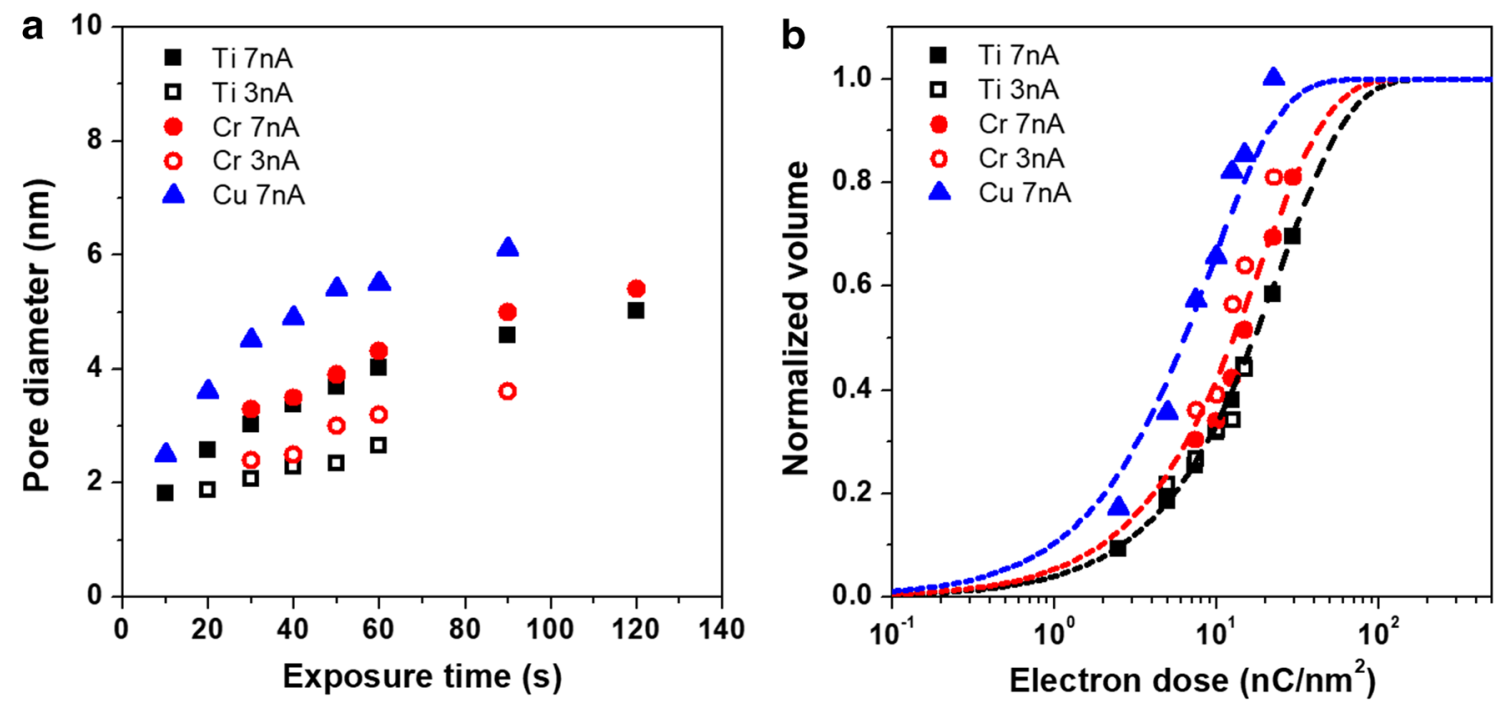

Fig. 3 a Pore diameters of $\mathrm{Ti}, \mathrm{Cr}$, and Cu membranes as a function of e-beam exposure time and $\mathbf{b}$ contrast curve of nanopore drilling

heaviest of the three analyzed metals. Since the e-beam current and probe size simultaneously changed as the e-beam current through the aperture of the $\mathrm{CL}$ in the TEM instrument changed, we introduced the characteristic contrast curve plotting the normalized drilling volume as a function of the electron dose $\left(\mathrm{nA} / \mathrm{cm}^{2}\right)$ to define the drilling amount as the electron dose. Therefore, we changed the plot of the diameter vs. exposure time to that of the normalized drilling volume vs. electron dose, as shown in Fig. 3b.

The e-beam exposure time can be converted into electron dose $\left(\mathrm{nC} / \mathrm{nm}^{2}\right)$, representing the number of electrons impinging on the membrane per unit area. To obtain the normalized volume, the drilled volume was calculated first using the formula: $\left[\pi \times(\text { diameter } / 2)^{2} \times\right.$ thickness $]$,

assuming a cylindrical shape and, then, was normalized by the saturated drilled volume. Figure $3 b$ shows the contrast curve of nanopore drilling for different metal membranes. It was revealed that the same dose of electrons was needed for the same drilling volume and the same metal membrane. In addition, it is worth noting that the contrast curve shifted toward higher electron doses in order from $\mathrm{Cu}$ to $\mathrm{Cr}$ and $\mathrm{Ti}$.

Under the assumption that atoms are removed from the specimen by the interaction with the e-beam, the reacted volume can be expressed by the simple reaction kinetics for exponential decay $[21,23]$ :

$$
\frac{\mathrm{N}_{\mathrm{d}}}{\mathrm{N}_{0}}=1-\exp \left[(-\sigma J t)^{n}\right]
$$

where $\mathrm{N}_{\mathrm{d}}$ is the number of drilled atoms, $\mathrm{N}_{0}$ is the initial number of atoms, $\sigma$ is the cross section $\left(\mathrm{m}^{2}\right), \mathrm{J}$ is the electron current density $\left(\mathrm{e} / \mathrm{s} \mathrm{m}^{2}\right), \mathrm{t}$ is the exposure time (s) and $\mathrm{n}$ is the kinetic order. Here, $\mathrm{N}_{\mathrm{d}} / \mathrm{N}_{0}$ is the normalized volume. We performed the fitting of Fig. 3b using this equation. The slope of the contrast curve represents the reaction order for the pure metal sample, and is well fitted with the first order reaction $(\mathrm{n}=1)$, which is different for the $\mathrm{Si}_{3} \mathrm{~N}_{4}$ [5] and TiN membranes [24] $(\mathrm{n}=2)$. It has been reported that light element of oxides and nitrides selectively dissipate after their initial exposure to the e-beam [21]. Consequently, it is believed that the higher kinetic orders of oxide and nitride membranes are caused by the promotion of overall atomic dissipation due to light element sputtering.

From the fitting of the contrast curve, we were able to obtain the atomic displacement cross-sections (sputtering cross-sections) and sputtering energies for perforation. Figure $4 \mathrm{a}$ and $\mathrm{b}$ shows the theoretical calculations and experimental values of sputtering cross-sections and energies, respectively. The experimentally obtained cross-section values were closer to the elastic scattering cross section value $\left(\sim 10^{-24} \mathrm{~cm}^{2}\right)$ and the tendency of the experimental values to decrease as the atomic weight increased was in agreement with that of the calculated values based on the knock-on damage in Fig. 1 . This dependency of the contrast curve on the membrane material demonstrated that nanopore drilling was mainly controlled by the direct atomic displacement. The sputtering energies of $\mathrm{Ti}, \mathrm{Cr}$, and $\mathrm{Cu}$ determined from the experimental sputtering cross-sections in Fig. 4a were approximately 10,9 , and $7 \mathrm{eV}$, respectively, which were 

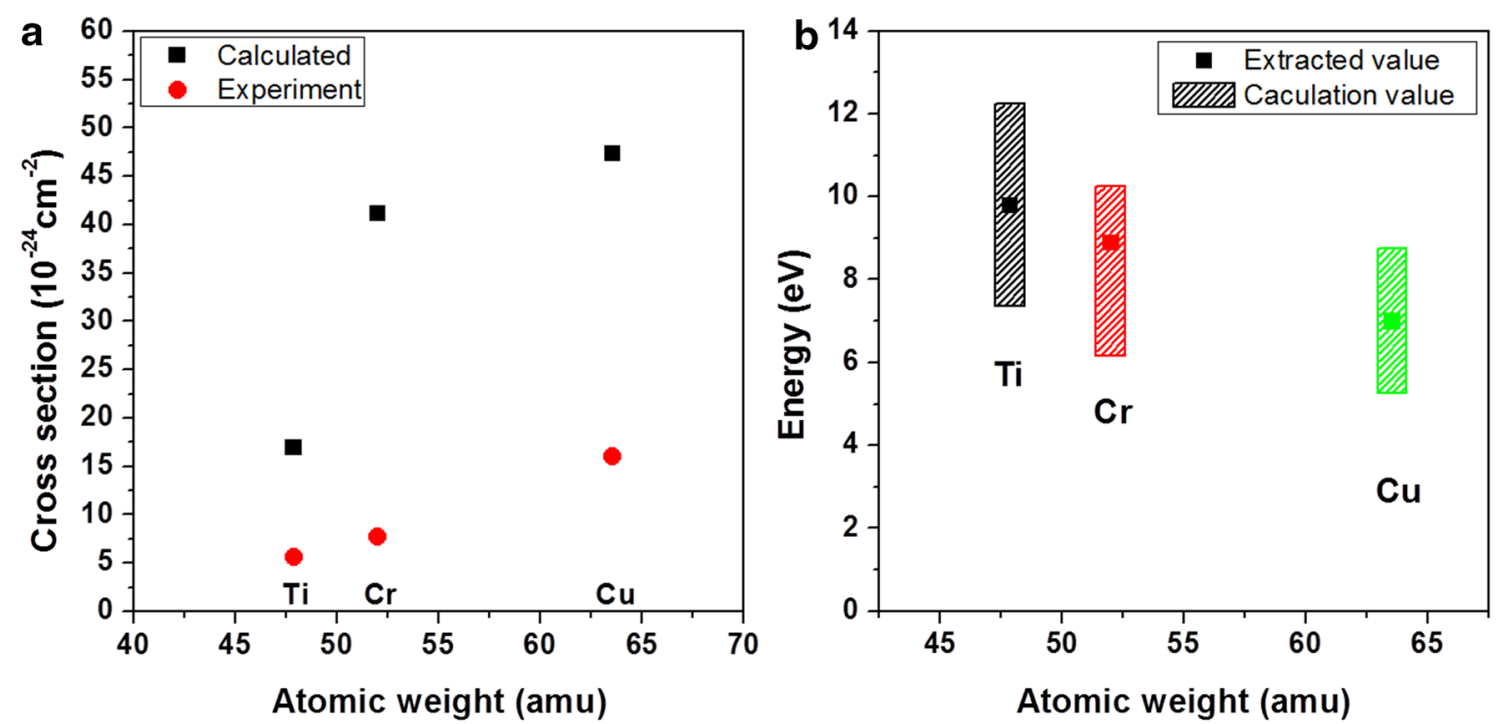

Fig. 4 Calculated vs. experimental values of $\mathbf{a}$ displacement cross-section and $\mathbf{b}$ displacement energy

in the range of the $E_{s}$ values reported in Table 1 (Fig. 4b). Therefore, nanopore evolution kinetics when using high energy e-beams was determined by the bonding energy as well as the atomic mass of the target atom. When the membrane material is the same, the atomic mass does not change, but the bonding status can vary due to the fabrication method. Therefore, the sputtering energy required to remove the surface atoms is influenced by the bonding state of the surface atoms, which would influence the scattering cross-section.

\section{Summary}

We first summarized the two interaction mechanisms between the fast electrons and atoms at rest, viz. the elastic scattering accompanying the direct atomic displacement caused by the kinetic energy transfer and the inelastic scattering involving the ionization or excitation caused by the electron-electron collisions. We concluded that nanopore drilling using focused e-beams was governed by the direct atomic displacement or sputtering. We calculated the direct atomic displacement cross-sections of several metals. $\mathrm{Al}, \mathrm{Ti}, \mathrm{Cr}, \mathrm{Cu}$, and $\mathrm{Au}$ were selected to investigate the effect of the displacement energy and atomic mass on nanopore drilling. As the atomic mass increased, the effect of the elastic scattering decreased, overall. We were unable to drill nanopores in the $30 \mathrm{~nm}$ thick Au membrane using a $200 \mathrm{kV}$ e-beam. We investigated the evolution of nanopores with the e-beam exposure time and obtained characteristic contrast curves for the $\mathrm{Ti}, \mathrm{Cr}$, and $\mathrm{Cu}$ membranes. While $\mathrm{M}_{\mathrm{Ti}}<\mathrm{M}_{\mathrm{Cr}}<\mathrm{M}_{\mathrm{Cu}}$, the corresponding $\mathrm{E}_{\mathrm{sub}}$ values for these metals showed an opposite trend. The experimental cross-sections obtained from the contrast curves were good matches for the calculated cross-sections based on elastic scattering. The sputtering energies of $\mathrm{Ti}, \mathrm{Cr}$, and $\mathrm{Cu}$ determined using the experimental sputtering crosssection were approximately 10,9 , and $7 \mathrm{eV}$, respectively, and were within the normally accepted sputtering energy range calculated using the $\mathrm{E}_{\text {sub }}$ values.

\section{Author's contributions}

HMK: experiment, analysis, and writing; KBP, HJK, HC, JSY, KL, KBK: analysis and discussion. All authors read and approved the final manuscript.

\section{Author details}

${ }^{1}$ Research Institute of Advanced Materials (RIAM), Seoul National University, Seoul, South Korea. ${ }^{2}$ Department of Materials Science and Engineering, Seoul National University, Seoul, South Korea.

\section{Acknowledgements}

This research was supported by the Nano Material Technology Development Program through the National Research Foundation of Korea (NRF) funded by Ministry of Science and ICT (MSIT) of Korea (2015M3A7B4050454) and (2017R1D1A1B03035058). This research was also supported by BioNano Health-Guard Research Center funded by the Ministry of Science and ICT (MSIT) of Korea as Global Frontier Project (H-GUARD_2013M3A6B2078943).

\section{Competing interests}

The authors declare that they have no competing interests.

\section{Availability of dada and materials}

The datasets used and/or analysed during the current study are available from the corresponding author on reasonable request.

\section{Funding}

1. The Nano Material Technology Development Program through the National Research Foundation of Korea (NRF) funded by Ministry of Science and ICT (MSIT) of Korea (2015M3A7B4050454) and (2017R1D1A1B03035058)

2. BioNano Health-Guard Research Center funded by the Ministry of Science and ICT (MSIT) of Korea as Global Frontier Project (H-GUARD_2013M3A6B2078943). 


\section{Publisher's Note}

Springer Nature remains neutral with regard to jurisdictional claims in published maps and institutional affiliations.

Received: 20 September 2018 Accepted: 19 October 2018

Published online: 12 November 2018

\section{References}

1. A.J. Storm, J.H. Chen, X.S. Ling, H.W. Zandbergen, C. Dekker, Fabrication of solid-state nanopores with single-nanometre precision. Nat. Mater. 2(8), 537-540 (2003)

2. S.D. Berger, I.G. Salisbury, R.H. Milne, D. Imeson, C.J. Humphreys, Electron energy-loss spectroscopy studies of nanometer-scale structures in alumina produced by intense electron-beam irradiation. Philos. Mag. B 55(3), 341-358 (1987)

3. D. Williams, C.B. Carter, Transmission electron microscopy (Springer, US, 1996), p. 65

4. H.-M. Kim, M.H. Lee, H.-S. Lee, J.-S. Wi, K. Lim, K.-B. Kim, Method of improving the quality of nanopatterning in atomic image projection electronbeam lithography. J. Vac. Sci. Technol. B 27(6), 2553-2557 (2009)

5. H.M. Kim, M.H. Lee, K.B. Kim, Theoretical and experimental study of nanopore drilling by a focused electron beam in transmission electron microscopy. Nanotechnology 22(27), 275303 (2011)

6. W.H. Pitchford, H.-J. Kim, A.P. Ivanov, H.-M. Kim, J.-S. Yu, R.J. Leatherbarrow, T. Albrecht, K.-B. Kim, J.B. Edel, Synchronized optical and electronic detection of biomolecules using a low noise nanopore platform. ACS Nano 9(2), 1740-1748 (2015)

7. Z.J. Jiang, D. Stein, Charge regulation in nanopore ionic field-effect transistors. Phys. Rev. E 83(3), 031203 (2011)

8. B.M. Venkatesan, D. Estrada, S. Banerjee, X.Z. Jin, V.E. Dorgan, M.H. Bae, N.R. Aluru, E. Pop, R. Bashir, Stacked graphene-Al2O3 nanopore sensors for sensitive detection of DNA and DNA-protein complexes. ACS Nano 6(1), 441-450 (2012)

9. S. Harrer, P.S. Waggoner, B.Q. Luan, A. Afzali-Ardakani, D.L. Goldfarb, H.B. Peng, G. Martyna, S.M. Rossnagel, G.A. Stolovitzky, Electrochemical protection of thin film electrodes in solid state nanopores. Nanotechnology 22(27), 275304 (2011)
10. S.-W. Nam, M.J. Rooks, K.-B. Kim, S.M. Rossnagel, lonic field effect transistors with sub-10 nm multiple nanopores. Nano Lett. 9(5), 2044-2048 (2009)

11. W.A. Mckinley, H. Feshbach, The coulomb scattering of relativistic electrons by nuclei. Phys. Rev. 74(12), 1759-1763 (1948)

12. N. F. Mott, H. S. W. Massey, The theory of atomic collisions, 2nd Edn, by N. F. Mott, H. S. W. Massey. Clarendon Press (printed by C. Batey); 1949

13. L.W. Hobbs, The theory of atomic collisions, in Introduction to analytical electron microscopy, ed. by J.J. Hren, G.I. Joseph, J.C. David (Plenum Press, New York, 1977), p. 437

14. W.M. Haynes, CRC handbook of chemistry and physics, 90th edn. (Taylor \& Francis, Abingdon, 2009)

15. O.S. Oen, Cross section for atomic displacements in solids by fast electrons (Oak Ridge National Laboratory, Oak Ridge, 1977)

16. W.E. King, R. Benedek, K.L. Merkle, M. Meshii, Damage effects of highenergy electrons on metals. Ultramicroscopy 23(3-4), 345-353 (1987)

17. C.R. Bradley, N.J. Zaluzec, Atomic sputtering in the analytical electronmicroscope. Ultramicroscopy 28(1-4), 335-338 (1989)

18. F. Seitz, On the disordering of solids by action of fast massive particles. Discuss. Faraday Soc. 5, 271 (1949)

19. Z.J. Jiang, M. Mihovilovic, J. Chan, D. Stein, Fabrication of nanopores with embedded annular electrodes and transverse carbon nanotube electrodes. J. Phys. Condens. Mat. 22(45), 454114 (2010)

20. T.J. Bullough, Sputtering and the formation of nanometre voids and holes in aluminium in a scanning transmission electron microscope. Philos. Mag. A 75(1), 69-85 (1997)

21. D.G. Howitt, S.J. Chen, B.C. Gierhart, R.L. Smith, S.D. Collins, The electron beam hole drilling of silicon nitride thin films. J. Appl. Phys. 103(2), $024310(2008)$

22. H.S. Lee, B.S. Kim, H.M. Kim, J.S. Wi, S.W. Nam, K.B. Jin, Y. Arai, K.B. Kim, Electron beam projection nanopatterning using crystal lattice images obtained from high resolution transmission electron microscopy. Adv. Mater. 19(23), 4189-4193 (2007)

23. D.A. Porter, K.E. Easterling, M. Sherif, Phase transformations in metals and alloys (Revised Reprint), 3rd edn. (Taylor \& Francis, Abingdon, 2009)

24. H.M. Kim, S.Y. Cho, K.B. Kim, Nanopore formation in TiN membranes by the focused electron beam of a transmission electron microscope. J .Vac. Sci. Technol. B 33(6), 06F502 (2015)

\section{Submit your manuscript to a SpringerOpen ${ }^{\circ}$ journal and benefit from:}

- Convenient online submission

- Rigorous peer review

- Open access: articles freely available online

- High visibility within the field

- Retaining the copyright to your article

Submit your next manuscript at $\boldsymbol{\nabla}$ springeropen.com 